\title{
THE EQUIPMENT FOR DETERMINING THE IMPACT OF TRAFFIC ENVIRONMENT ON ROAD PAVEMENT
}

\author{
Iryna SOLONENKO
}

\begin{abstract}
The article presents the classification of equipment developed by the author for the research of the operational characteristics of road pavement. The equipment was classified according to the following criteria: type of equipment; type of contact element; mode of interaction with the supporting surface; type of fixture of the suspension element; number of contact elements; sample type; type of load. For illustrations, the classification of the most common equipment was carried out. The research was conducted to compare and select the most rational equipment to study the effect of traffic environment on the road pavement. The research was carried out by the multi-criteria analysis. Based on the conducted research, the most rational installations for conducting experiments were determined.
\end{abstract}

Keywords: classification; installation; load; multi-criteria analysis; road pavement; traffic environment; wheel

\section{INTRODUCTION}

The condition of roads is mainly determined by the quality of the road pavement. Basically, the road pavement is influenced by:

- the traffic environment, which depends on the intensity and the combination of vehicles;

- the climatic conditions determined by the location of the examined length of the road (temperature, humidity).

A moving traffic environment, acting on the road pavement, causes various types of defects (wear-at, abrasion, formation of plastic crack, chipping, peeling, etc.) [1-3]. The reason behind the formation of defects depends on the properties of the road pavement materials, the design features of the wheel running gear of cars and the speed of traffic.

The most widespread roads are with a pavement of cement concrete and asphalt concrete. Each of the examined materials of the pavement has its own type of wear and tear. On asphalt, over time, due to the usage of pavements, rutting (plastic deformation of the covering caused by the impact of the wheel) appears on roads.

Rutting leads to a decrease in vehicle traffic safety and impairs vehicle handling (Fig. 1a and 1b) [2, 4].

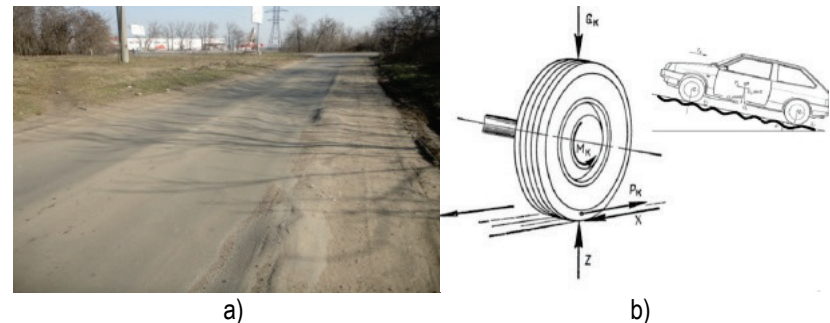

Figure 1 Rut on the road: a) the rut on the road; b) wheel action on the road pavement

On roads with asphalt concrete, there are other types of deformations for road pavement: waviness (occurs because of the longitudinal deformations of the road pavement); cracks; pits (caused by vertical deformations of the road pavement).

For hard road surface (cement concrete), the most typical types of wear are: chipping, peeling (caused by the effect of the freeze-thaw temperature); abrasion (occurs to the abrasive effect of the wheels).

\section{RESULTS AND DISCUSSION}

The study of the influence of the impact of wheel running gear on the road pavement is most often carried out on installations and devices that create dynamic effects on the material pavement. As a rule, these are: laboratory, testing bench, full-size.

Analysis of works [1-13] showed that there is currently no classification for this type of equipment.

The purpose of the research was to develop a classification of equipment that is used to study the effect of transport on road pavements.

To achieve the above-mentioned purposes, the following problems were resolved:

- to propose a block diagram of classifications;

- to propose a methodology for the use of classifications;

- to conduct a multi-criteria analysis of the existing stands and equipment;

- to develop a criterion for assessing the properties of the equipment;

- to develop a rating scale of the equipment;

- to develop recommendations for the selection of rational equipment.

In the paper, a classification for the equipment presented in Tab. 1 is proposed. The classification is carried out according to the following criteria: type of equipment; type of contact element; mode of interaction with the supporting surface; type of attachment of the suspension element; number of contact elements; sample type; type of load. Each criterion is divided into classes: With the sample heating; Without the sample heating; Mobile; Rotative; Landfills; 
Natural; Flat contact element; Wheel non-deformable; Wheel elastic; The wheel to which the torque is applied; Wheel that is free to roll; Not flexible; Moving translational, Moving rotational, Free, One, Two, More than two; Cuboid, Cylinder, Cuboid and Cylinder; Vertical, Vertical + Horizontal, Vertical + Horizontal + Centrifugal .

Table 1 Classification of the equipment for the study of the operational characteristics of road pavements

\begin{tabular}{|l|l|c|}
\hline \multicolumn{3}{|c|}{ characteristics of road pavements } \\
\hline No. & \multicolumn{1}{|c|}{$\begin{array}{c}\text { Classifications of the equipment by } \\
\text { signs }\end{array}$} & Classes of signs \\
\hline $\mathrm{I}$ & TYPE OF EQUIPMENT & \\
\hline $\mathrm{I}_{1}$ & Laboratory & With the sample heating \\
\hline $\mathrm{I}_{12}$ & & $\begin{array}{c}\text { Without the sample } \\
\text { heating }\end{array}$ \\
\hline $\mathrm{I}_{13}$ & & \\
\hline $\mathrm{I}_{2}$ & Test-bench & Mobile \\
\hline $\mathrm{I}_{21}$ & & Rotative \\
\hline $\mathrm{I}_{22}$ & & \\
\hline
\end{tabular}

a)

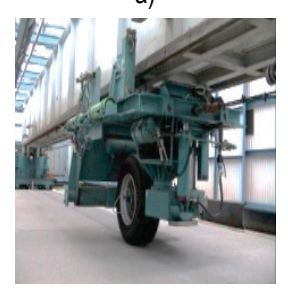

d)

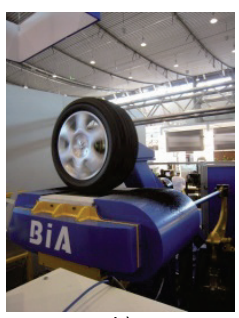

b)

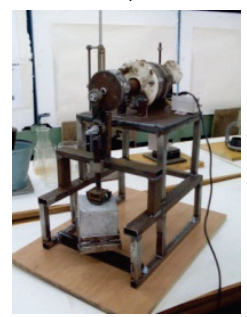

e)

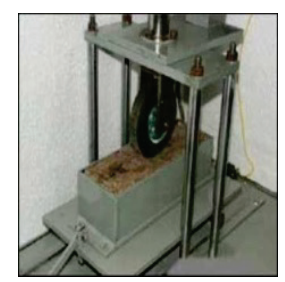

c)

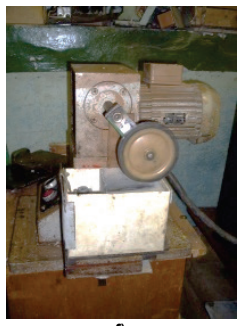

f)
Figure 2 The name of the installation (formula by classifications): a) the testing bench Wheel Tracking Device $\left(I_{1}+I_{2}+I I_{2}+I V_{2}+V_{1}+V I_{1}+V I_{1}\right)$; b) the testing bench dynamometer BIA $\left.\left(I 1_{3}+I_{3}+I I_{1}+I V_{1}+V_{1}+V I_{2}+V I_{2}\right) ; c\right)$ the testing bench of the State Research Institute, Ukraine $\left(\mathrm{l}_{13}+\mathrm{II}_{3}+\mathrm{III}_{2}+\mathrm{IV}_{2}+\mathrm{V}_{1}+\mathrm{VI}+\right.$ $\mathrm{VII} 2)$; d) one-wheeled installation Lintrack, Netherlands $\left(\mathrm{II}_{3}+\mathrm{II}_{3}+\mathrm{II}_{1}+\mathrm{IV}_{2}+\mathrm{V}_{1}+\right.$ $\left.\mathrm{VI}_{1}+\mathrm{VII}_{2}\right)$; e) developed the testing bench by the author BUSOL-1, Odessa, Ukraine $\left(I_{13}+I_{1}+I V_{2}+V_{1}+V I_{3}+V I_{1}\right) ;$ f $)$ the testing bench developed by the author BUSOL-2 $\left(\mathrm{I}_{13}+\mathrm{II}_{3}+\mathrm{III}_{2}+\mathrm{IV}_{3}+\mathrm{V}_{1}+\mathrm{VI}_{3}+\mathrm{VII}\right)$

- The testing bench - the dynamometer BIA, Tolyatti at the plant of LLC "Bia". The testing bench is designed to study the interaction of the vehicle suspension with the road pavement. For road pavement testing, the sample can be made in the form of a cylinder. The testing bench has a wheel load of $7 \mathrm{kN}$ and a treadmill speed of up to $250 \mathrm{~km} / \mathrm{h}$ (Fig. 2b) [14].

- Installation of the State Research Institute, Ukraine (Fig. $2 c)$. The installation uses reciprocating movements of the tray with the road pavement material with a frequency of 48 passes per 1 minute $(50 \mathrm{~km} / \mathrm{h})[2,4]$.

The combination of the criteria and classes allows you to describe the equipment that is being considered. Example:

$\mathrm{I}_{1}+\mathrm{II}_{2}+\mathrm{III}_{2}+\mathrm{IV}_{2}+\mathrm{V}_{1}+\mathrm{VI}_{1}+\mathrm{VII}_{1}$,

Where: $\mathrm{I}_{1}$ - laboratory; $\mathrm{II}_{2}$ - wheel non-deformable; $\mathrm{III}_{2}-$ wheel that is free to roll; $\mathrm{IV}_{2}$ - the suspension is movable; $\mathrm{V}_{1}$ - one contact element; $\mathrm{VI}_{1}$ - the test sample has the form of a cuboid; $\mathrm{VII}_{1}$ - the load that acts vertically on the contact element.

The examples of the classifications of the existing laboratory equipment are shown in Fig. 2.
- One-wheel installation Lintrack in the Netherlands. The installation has a wheel load from 15 to $100 \mathrm{kN}$ and a speed of up to $20 \mathrm{~km} / \mathrm{h}$ (Fig. 2d)) [4].

- The author has developed the testing benches BUSOL-1 and BUSOL-2 (Fig. 2e and 2f) [5]. The testing benches are designed to assess the abrasion and deformation of the road pavement of various types, both in the dry and wet state.

Due to the mobile test benches, research of the physicomechanical and operational characteristics of the road on any of its parts (Fig. 3a) [2, 4] can be conducted. 


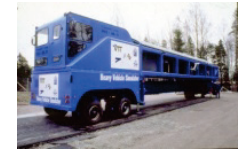

a)

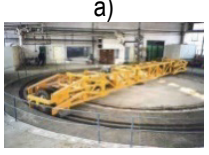

d)

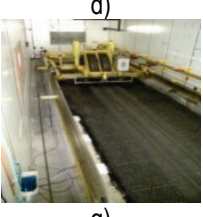

g)

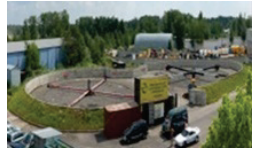

b)

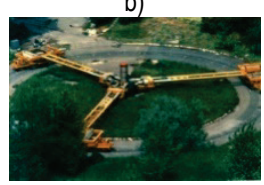

e)

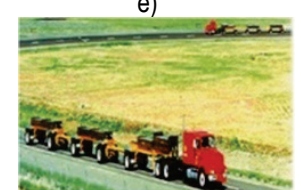

h)

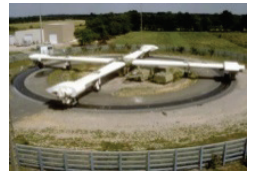

c)

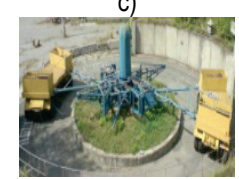

f)

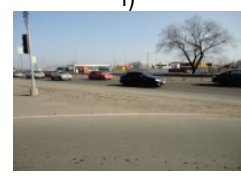

i)
Figure 3 Installations for pavement research: a) The mobile test benches HVS- Mark IV, USA $\left(I_{21}+I_{3}+I I_{1}+I V_{2}+V_{1}+V l_{1}+V I I_{1}\right)$; b) The onewheeled vehicle "Carousel" MADI, Moscow, Russia $\left(\mathrm{I}_{22}+\mathrm{II}_{3}+\mathrm{II}_{2}+\mathrm{IV}_{3}+\right.$ $\left.\left.\mathrm{V}_{3}+\mathrm{VI}_{1}+\mathrm{VII}_{2}\right) ; \mathrm{c}\right)$ The four-wheeled installation LCPC, France $\left(\mathrm{I}_{22}+\mathrm{II}_{3}+\mathrm{III}_{1}\right.$ $\left.+I V_{2}+V_{3}+V l_{1}+V I_{2}\right)$; d) The two-wheeled installation in Romania, the city of lasi $\left(I_{22}+I_{3}+I I_{2}+I V_{2}+V_{3}+V I_{1}+V I_{2}\right)$; e) The two-wheeled installation Vuis-Cestu, Slovakia $\left(I_{22}+I_{3}+I I I_{1}+I V_{2}+V_{3}+V I_{1}+V I_{2}\right) ;$ f $)$ The circular testing bench in Kiev, Ukraine $\left.\left(I_{22}+I_{3}+I I_{1}+I V_{2}+V_{3}+V I_{1}+V I I_{2}\right) ; g\right)$ The two-wheeled installation Danish Road Testing Machine, Denmark $\left(\mathrm{l}_{13}+\mathrm{Il}_{3}+\right.$ $\left.\left.\mathrm{III}_{1}+\mathrm{IV}_{2}+\mathrm{V}_{1}+\mathrm{VI}_{1}+\mathrm{VI} \mathrm{I}_{2}\right) ; \mathrm{h}\right)$ The landfills MinRoad, USA $\left(\mathrm{I}_{31}+\mathrm{II}_{3}+\mathrm{IV}_{4}+\right.$ $\left.\mathrm{V}_{3}+\mathrm{VI}_{1}+\mathrm{VII}\right)$; i) The road pavement testing in full-scale conditions $\left(\mathrm{I}_{31}+\mathrm{II}_{3}\right.$ $\left.+\mathrm{IV}_{4}+\mathrm{V}_{3}+\mathrm{VI} \mathrm{I}_{1}+\mathrm{VI} \mathrm{I}_{2}\right)$

The use of full-size installations allows a more adequate assessment of the impact of traffic environment on road pavement. They are performed in the form of a rotating installation. Let us examine some of them:

- The one-wheeled installation KUIDM-2 "Carousel" in Moscow, Russia provides a speed of up to $80 \mathrm{~km} / \mathrm{h}$ (Fig. $3 b)$.
- The four-wheeled rotating installation Laboratoire Central des Ponts and Chaussees (LCPC) was made in France. The installation has: a diameter of rotation of 30 and $40 \mathrm{~m}$; a wheel load of up to $75 \mathrm{kN}$; the maximum speed of movement of up to $105 \mathrm{~km} / \mathrm{h}$ (Fig. 3c).

- The two-wheeled installation in Iasi, Romania (Fig. 3d).

- The two-wheeled installation Vuis-Cestu in Slovakia. The installation has: a diameter $32 \mathrm{~m}$; a wheel speed of up to $50 \mathrm{~km} / \mathrm{h}$ (Fig. 3e).

- The circular testing bench in Kiev, Ukraine. The installation has: a wheel load of up to $75 \mathrm{kN}$, a wheel speed of up to $40 \mathrm{~km} / \mathrm{h}$ (Fig. 3f).

- The two-wheeled installation Danish Road Testing Machine (DRTM). The unit has: a wheel load of up to 65 $\mathrm{kN}$; a speed of up to $30 \mathrm{~km} / \mathrm{h}$ (Fig. $3 \mathrm{~g}$ ).

Apart from the rotating testing bench for the research of the properties of road pavement, test landfills with heavy equipment can be used (Fig. 3h), and testing can be carried out in full-scale conditions (Fig. 3i).

The installations that were shown in the Figs. 2 and 3 were evaluated according to the following criteria: the equipment cost; the research cost; the need for control from the operator's side; the maintenance and repair costs; the price of manufacture and installation of the sample; the ease of use; the measured parameters; the number of the types of coverage; the regulation of sample tests conditions; the protection from environmental exposure; the wheel speed; the cycling of the load.

For the ease of comparison of the testing bench and the installations for each of the criteria, appropriate comparison scales were developed (Tab. 2).

The coded values, descriptions of the testing bench and installations researched in the work are presented in Tab. 3.

Table 2 Criteria and scale rating criteria

\begin{tabular}{|c|c|c|c|c|c|c|}
\hline \multirow{2}{*}{ No. } & \multirow[b]{2}{*}{ Criterion } & \multicolumn{2}{|r|}{$\leftarrow$ the worse } & \multicolumn{3}{|c|}{ Comparison scale the best $\rightarrow$} \\
\hline & & 1 & 2 & 3 & 4 & 5 \\
\hline 1 & The equipment cost & very high & high & medium & low & insignificant \\
\hline 2 & The research cost & very high & high & medium & low & insignificant \\
\hline 3 & The need for control from the operator's side & $\begin{array}{c}\text { two or more } \\
\text { people }\end{array}$ & constant & periodic & $\begin{array}{l}\text { start and end of } \\
\text { the experience }\end{array}$ & not required \\
\hline 4 & The maintenance and repair costs & very high & high & medium & low & insignificant \\
\hline 5 & The price of the manufacture and installation of the sample & very high & high & medium & low & insignificant \\
\hline 6 & The ease of use & very low & low & average & high & very high \\
\hline 7 & The measured parameters & one & two & three & four & five or more \\
\hline 8 & The number of the types of pavement* & one & two & three & four & five or more \\
\hline 9 & The regulation of sample tests conditions & unregulated & $\begin{array}{l}\text { depending on } \\
\text { the environment }\end{array}$ & $\begin{array}{l}\text { temperature } \\
\text { change }\end{array}$ & $\begin{array}{l}\text { temperature and } \\
\text { humidity }\end{array}$ & $\begin{array}{l}\text { temperature, } \\
\text { humidity and } \\
\text { contact pressure }\end{array}$ \\
\hline 10 & The protection from environmental exposure & none & $\begin{array}{c}\text { from } \\
\text { precipitation }\end{array}$ & partially & $\begin{array}{c}\text { in a heated } \\
\text { laboratory space }\end{array}$ & completely \\
\hline 11 & The wheel speed & missing & low & $\begin{array}{c}\text { medium up to } 50 \\
\mathrm{~km} / \mathrm{h}\end{array}$ & $\begin{array}{l}\text { high } 50 \mathrm{~km} / \mathrm{h} \\
\text { and more }\end{array}$ & $\begin{array}{l}\text { very high more } \\
\text { than } 100 \mathrm{~km} / \mathrm{h}\end{array}$ \\
\hline 12 & The cycling of the load & there are no 10 & low $10-20$ & average $20-50$ & high $50-100$ & very high \\
\hline
\end{tabular}

one - non-rigid; two - non-rigid, rigid; three - H, R, pavement; four - H, R, P, ground pavement; five - H, R, P, G, paving elements, etc.

The comparison of testing benches and installations were carried out by the method of expert assessments, the results are shown in Tab. 4. The data obtained in Tab. 4 are graphically represented in Fig. 4.
As it was shown by the results of the research presented in Tab. 4 (Fig. 4), the most rational equipment for determining the impact of traffic environment on the road pavement is: 
- The laboratory equipment: the Wheel Tracking Device (Fig. 4a); the State Research Institute, Ukraine (Fig. 4b); BUSOL-1, Ukraine (Fig. 4k); м) BUSOL-2 (Fig. 4l).

- The testing bench equipment: the mobile test benches HVS- Mark IV, USA (Fig. 4d); the one-wheeled vehicle "Carousel", Russia (Fig. 4f);

- The natural research: the road pavement testing in fullscale conditions, Odessa, Ukraine (Fig. 4j).

For the first of the installations examined, the disadvantage is the need for the heating of the sample of the material that is being tested. Such installation cannot be used for other types of coverage.

Table 3 The compared testing bench and installations

\begin{tabular}{|c|c|c|}
\hline No. & $\begin{array}{c}\text { Formulas of the testing bench } \\
\text { and installations }\end{array}$ & $\begin{array}{c}\text { Name of the testing bench and } \\
\text { installations }\end{array}$ \\
\hline 1 & $\begin{array}{c}\mathrm{I}_{12}+\mathrm{II}_{2}+\mathrm{III}_{2}+\mathrm{IV}_{2}+\mathrm{V}_{1}+\mathrm{VI}_{1}+ \\
\mathrm{VII}_{1}\end{array}$ & $\begin{array}{c}\text { The Wheel Tracking Device, } \\
\text { EU (Fig. 2a) }\end{array}$ \\
\hline 2 & $\begin{array}{c}\mathrm{I}_{13}+\mathrm{II}_{3}+\mathrm{III}_{2}+\mathrm{IV}_{2}+\mathrm{V}_{1}+\mathrm{VI}_{1}+ \\
\mathrm{VII}_{2}\end{array}$ & $\begin{array}{c}\text { The State Research Institute, } \\
\text { Ukraine (Fig. 2f) }\end{array}$ \\
\hline 3 & $\begin{array}{c}\mathrm{I}_{12}+\mathrm{II}_{3}+\mathrm{III}_{1}+\mathrm{IV}_{1}+\mathrm{V}_{1}+\mathrm{VI}_{2}+ \\
\mathrm{VII}_{2}\end{array}$ & $\begin{array}{c}\text { The dynamometer stand BIA, } \\
\text { Russia (Fig. 2b) }\end{array}$ \\
\hline 4 & $\begin{array}{c}\mathrm{I}_{21}+\mathrm{II}_{3}+\mathrm{III}_{1}+\mathrm{IV}_{2}+\mathrm{V}_{1}+\mathrm{VI}_{1}+ \\
\mathrm{VII}_{1}\end{array}$ & $\begin{array}{c}\text { The mobile test benches HVS- } \\
\text { Mark IV, USA (Fig. 2a) }\end{array}$ \\
\hline 5 & $\begin{array}{c}\mathrm{I}_{13}+\mathrm{II}_{3}+\mathrm{III}_{1}+\mathrm{IV}_{2}+\mathrm{V}_{1}+\mathrm{VI}_{1}+ \\
\mathrm{VII}_{2}\end{array}$ & $\begin{array}{c}\text { The one-wheeled installation } \\
\text { Lintrack, Netherlands (Fig. 2d) }\end{array}$ \\
\hline 6 & $\begin{array}{c}\mathrm{I}_{22}+\mathrm{II}_{3}+\mathrm{II}_{2}+\mathrm{IV}_{3}+\mathrm{V}_{3}+\mathrm{VI}_{1}+ \\
\mathrm{VII}_{2}\end{array}$ & $\begin{array}{c}\text { The one-wheeled vehicle } \\
\text { Carousel", Russia (Fig. 2b) }\end{array}$ \\
\hline 7 & $\begin{array}{c}\mathrm{I}_{22}+\mathrm{II}_{3}+\mathrm{III}_{1}+\mathrm{IV}_{2}+\mathrm{V}_{3}+\mathrm{VI}_{1}+ \\
\mathrm{VII}_{2}\end{array}$ & $\begin{array}{c}\text { The four-wheeled installation } \\
\text { LCPC, France (Fig. 2c) }\end{array}$ \\
\hline 8 & $\begin{array}{c}\mathrm{I}_{22}+\mathrm{II}_{3}+\mathrm{III}_{1}+\mathrm{IV}_{2}+\mathrm{V}_{3}+\mathrm{VI}_{1}+ \\
\mathrm{VII}_{2}\end{array}$ & $\begin{array}{c}\text { The circular testing bench, } \\
\text { Ukraine (Fig. 2f) }\end{array}$ \\
\hline 9 & $\mathrm{I}_{31}+\mathrm{II}_{3}+\mathrm{IV}_{4}+\mathrm{V}_{3}+\mathrm{VI}_{1}+\mathrm{VII}_{3}$ & $\begin{array}{c}\text { The landfills MinRoad, USA } \\
\text { (Fig. 2h) }\end{array}$ \\
\hline 10 & $\mathrm{I}_{31}+\mathrm{II}_{3}+\mathrm{IV}_{4}+\mathrm{V}_{3}+\mathrm{VI}_{1}+\mathrm{VII}_{2}$ & $\begin{array}{c}\text { The road pavement testing in } \\
\text { full-scale conditions (Fig. 2i) }\end{array}$ \\
\hline 11 & $\mathrm{I}_{13}+\mathrm{II}_{1}+\mathrm{IV}_{2}+\mathrm{V}_{1}+\mathrm{VI}_{3}+\mathrm{VII}_{1}$ & BUSOL-1, Ukraine (Fig. 2e) \\
\hline 12 & $\mathrm{I}_{13}+\mathrm{II}_{3}+\mathrm{III}_{2}+\mathrm{IV}_{3}+\mathrm{V}_{1}+\mathrm{VI}_{3}+$ & BUSOL-2, Ukraine (Fig. 2f) \\
\hline
\end{tabular}

Table 4 The comparison of the testing benches and installations

\begin{tabular}{|l|l|l|l|l|l|l|l|l|l|l|l|l|}
\hline \multicolumn{1}{|c|}{ The criterion } & 1 & 2 & 3 & 4 & 5 & 6 & 7 & 8 & 9 & 10 & 11 & 12 \\
\hline The equipment cost & 5 & 3 & 2 & 2 & 4 & 2 & 1 & 2 & 1 & 3 & 5 & 5 \\
\hline The research cost & 4 & 5 & 3 & 3 & 4 & 2 & 1 & 2 & 1 & 4 & 5 & 5 \\
\hline The need for control & 3 & 4 & 2 & 2 & 3 & 2 & 1 & 1 & 1 & 3 & 4 & 4 \\
\hline $\begin{array}{l}\text { The maintenance and } \\
\text { repair costs }\end{array}$ & 4 & 4 & 3 & 3 & 3 & 2 & 1 & 2 & 1 & 4 & 4 & 5 \\
\hline $\begin{array}{l}\text { The price of the } \\
\text { manufacture and } \\
\text { installation of the } \\
\text { sample }\end{array}$ & 5 & 4 & 3 & 2 & 3 & 2 & 1 & 2 & 1 & 3 & 5 & 5 \\
\hline The ease of use & 4 & 3 & 4 & 2 & 4 & 3 & 2 & 2 & 3 & 3 & 4 & 5 \\
\hline $\begin{array}{l}\text { The measured } \\
\text { parameters }\end{array}$ & 5 & 3 & 3 & 4 & 4 & 3 & 2 & 2 & 2 & 5 & 4 & 5 \\
\hline $\begin{array}{l}\text { The number of the } \\
\text { types of pavement* }\end{array}$ & 1 & 2 & 2 & 5 & 2 & 2 & 3 & 2 & 3 & 5 & 3 & 4 \\
\hline $\begin{array}{l}\text { The regulation of } \\
\text { ample tests } \\
\text { conditions }\end{array}$ & 4 & 4 & 3 & 2 & 3 & 1 & 1 & 1 & 1 & 1 & 4 & 5 \\
\hline $\begin{array}{l}\text { The protection from } \\
\text { environmental } \\
\text { exposure }\end{array}$ & 5 & 5 & 5 & 2 & 5 & 1 & 1 & 1 & 1 & 1 & 5 & 5 \\
\hline The wheel speed & 3 & 3 & 5 & 3 & 2 & 5 & 5 & 1 & 3 & 5 & 3 & 4 \\
\hline $\begin{array}{l}\text { The cycling of the } \\
\text { load }\end{array}$ & 3 & 3 & 5 & 3 & 3 & 4 & 4 & 4 & 5 & 4 & 3 & 5 \\
\hline
\end{tabular}

The installation of the State Scientific Research Institute, Ukraine (Fig. 4b) is deprived of the disadvantages of the above mentioned equipment. The disadvantage of this installation is the low speed of movement of the chute with a sample of material. The equipment BUSOL-1 (Fig. 4b), BUSOL-2 (Fig. 41) is deprived of the drawbacks of the installations that were examined earlier. Due to it, it is possible to explore samples of asphalt, cement concrete and other types of road pavement. For the experiments, samples of cubic and cylindrical shapes can be used. The samples can be tested dry and wet.

The examined rotating installation (Fig. $4 \mathrm{f}$ ) provides a speed of up to $50 \mathrm{~km} / \mathrm{h}$. The disadvantage of this installation is: very large, occupied space; the high cost of research; the insufficient speed for modeling the interaction of the wheel and the coverage on highways; influence of climatic conditions.

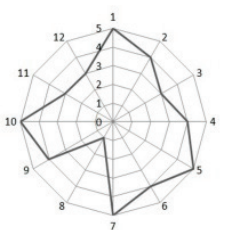

a)

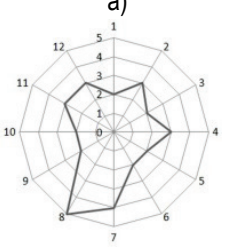

d)

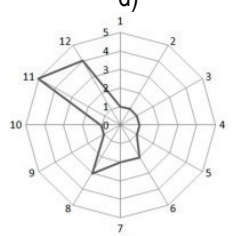

g)

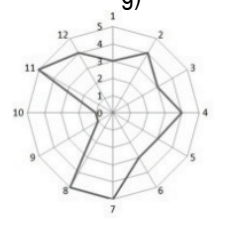

j)

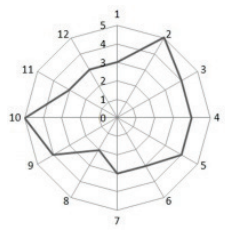

b)

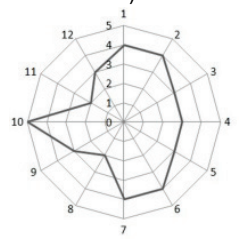

e)

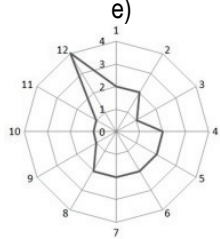

h)

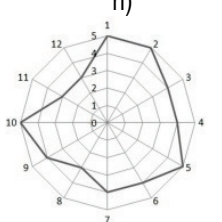

k)



c)



f)

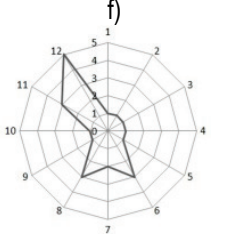

i)



l)
Figure 4 Multicriteria diagrams equipment:

a) The Wheel Tracking Device, EU; b) The State Research Institute, Ukraine; c) The dynamometer stand BIA, Russia; d) The mobile test benches HVSMark IV, USA; e) The one-wheeled installation Lintrack, Netherlands; f) The one-wheeled vehicle KUIDM-2 "Carousel", Russia; g) The four-wheeled installation LCPC, France; h) The circular testing bench, Ukraine; i) The landfills MinRoad, USA; j) The road pavement testing in full-scale conditions, Ukraine; k) BUSOL-1, Ukraine; I) BUSOL-2, Ukraine

For a field study (Fig. 4j), the shares should have devices that provide for the number of vehicles: its type, the speed of moving and load on the wheel. The disadvantage of this research is: the inability to control the speed and intensity of the traffic environment; the influence of climatic conditions. 


\section{CONCLUSIONS}

The concluded research enabled the following:

- to offer a classification of equipment for the research of the operational characteristics of road pavements;

- to conduct a multi-criterion analysis of the existing testing benches and installations intended for the study of the road pavement material;

- Based on a multi-criteria analysis, it was recommended to use the following equipment in the scientific and engineering practice: the Wheel Tracking Device; the testing bench of the State Research Institute, BUSOL-1, BUSOL-2; HVS-Mark IV, KUIDM-2 "Carousel" and field study on road pavement.

The use of the considered equipment will significantly reduce the cost and time to conduct research.

\section{REFERENCES}

[1] Vasiliev, A. P., et al. (2004). Repair and maintenance of highways: Road builder's reference encyclopedia. T. 2. - M.: Informavtodor, p. 507.

[2] Mozgovoy, V. V., Onishchenko, A. N., Prudky, A. V., Kutsman, A. M., Zhukov, A. A., Olkhovy,i B. N., et al. (2010). Experimental evaluation of the stability of asphalt concrete pavement to the formation of rut. Road machinery. St. Petersburg, 114-128.

[3] Golovko, S. K., Babinets, A. D., \& Fosch, I. V. (2004). Modern approach to the study of the formation of abrasion in asphalt concrete pavements. Roads and Bridges, 2, 115-123.

[4] Mozgovoy, V. V., Onishchenko, A. M., Prudky, O. V., Kutsman, O. M., Nevinglovskiy, V. F., et al. (2010). Testing of road constructions on a ring stand - successes, problems, perspectives (part 2). Roadster of Ukraine. Scientific and Production Magazine, 216(4), 24-31.

[5] Solonenko, I. P. (2012). Road quality assessment. Third Scientific and Practical Conference of Young Scientists and Students, ODATRA, Odessa, Ukraine, 217-220.

[6] Vasilyev, Y. E., Ivachev, A. V., \& Bratischev, I. S. (2014). Study of the stability of road construction materials to wear gauge in conditions close to operational. The Internet Journal "SCIENCE" Release, 24(5), 1-14. Access mode: $\mathrm{http}: / /$ naukovedenie.ru

[7] Bugaev, S.V. \& Solonenko, I. P. (2010). Determination of the change in the mass of the material sample by the amount of volume loss. Vestnik OGASA, 39, 50-58.

[8] Solonenko, I. (2019). Coating materials for bike paths. AllRussian every-month branch magazine "Construction: New technologists - new equipment", 1, 32-39.

[9] Solonenko, I. P. (2015). Ensuring performance coatings of concrete for roads, due to their modifications. Meriding ingineresc, 57(2), 38-40.

[10] Solonenko, I. P. \& Bugaev, S. V. (2017). Determination of the state of a bearing assembly using remote measurement of its heating temperature. Proceedings of Azerbaijan State Marine Academy, 2, 171-175.

[11] Solonenko, I. (2016). Influence on the quality of rigid road cover of additives and fillers. Scientific and technical collection "Automobile roads and road construction", 98, 268-278.

[12] Solonenko, I. (2014). Cementno betonski cestovni kolnici. Tehnički glasnik, 8(1), 45-47.
[13] Solonenko, I. (2017). Use of cement concrete as a coating for small airfields, heliports and access roads. XIII International Scientific and Technical Conference "AVIA-2017", NAU, Kyiv, 23.46-23.50.

[14] Dynamometer with six degrees of freedom. Access mode: http://bia.ru.com/automotive/car-dynamic/6-dofdynamometer/

\author{
Author contacts: \\ Iryna SOLONENKO, PhD, Head Teacher \\ Odessa State Academy of Civil Engineering and Architecture, \\ Ukraine, 65029 Odessa, Didrikhsona St. 4 \\ Tel./Fax: +380974666579 \\ E-mail: odarina08@rambler.ru
}

